\title{
Communicating Adverse Drug Reaction Insights Through Patient Organizations: Experiences from a Pilot Study in the Netherlands
}

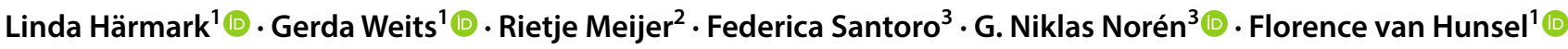

Published online: 16 May 2020

(c) The Author(s) 2020, corrected publication 2020

\begin{abstract}
Introduction To improve therapeutic decision making, it is crucial that information regarding adverse drug reactions reaches patients. It is not enough to disseminate such findings through regulatory and scientific channels; targeted efforts to reach patients are necessary. One possible avenue is to collaborate with patient organizations.

Objectives The aim of this pilot study was to explore how adverse drug reactions can be communicated through patient organizations.

Methods A text describing a signal of levothyroxine and panic attacks was tailored to patients' needs, in terms of language, style and content, with emphasis placed on what to do when experiencing the symptoms described. The signal was communicated via the Dutch thyroid organization's digital newsletter, social media channels, website and print magazine.

Results The digital newsletter was distributed to around 5000 subscribers. On Facebook, 13,820 people viewed the message, with 2346 clicks in the message, indicating an intention to read the whole post. The interactions on social media were positive, and the tone was respectful.

Conclusion Patient organizations can help enable effective communication of adverse drug reactions to a relevant audience. The social media post generated more engagement than other communications from the patient organization, indicating a strong interest in this information. The additional patient experiences that were shared in the comments on social media further strengthened the original signal and its relevance to patients, creating an interesting feedback loop. The favourable experiences in this study support further consideration and exploration of this approach to communicate adverse drug reactions to patients.
\end{abstract}

\section{Key Points}

It is important that adverse drug reaction insights are communicated to patients, with the aim to reduce harm.

Collaboration between a pharmacovigilance centre and a patient organization to communicate adverse drug reaction insights to patients is feasible.

Social media communication generates more engagement than other communication channels.

Linda Härmark

1.harmark@lareb.nl

1 Netherlands Pharmacovigilance Centre Lareb, Goudsbloemvallei 7, $5237 \mathrm{MH}$ 's-Hertogenbosch, The Netherlands

2 Netherlands Thyroid Organization, Stationsstraat 79 G, 3811 MH Amersfoort, The Netherlands

3 Uppsala Monitoring Centre, Bredgränd 7, Uppsala, Sweden

\section{Introduction}

The aim of pharmacovigilance is to reduce harm caused by adverse drug reactions, which requires that new knowledge reach the prescribers, dispensers and users of drugs. Effective communication with healthcare professionals and patients is essential [1-3]. Current channels for disseminating new information about adverse drug reactions include peer-reviewed scientific journals, the World Health Organization (WHO) Pharmaceuticals newsletter and the websites of drug regulatory authorities such as the European Medicines Agency and the US FDA. However, these channels may not suffice, as they are rarely found by healthcare professionals or patients searching for information, and these people may not be searching for the information to begin with. Therefore, the pharmacovigilance community needs to proactively reach out with messages that are tailored to this specific audience.

The interests and needs of many patients and their families are represented by patient organizations. These are usually not-for-profit institutions with dissemination of information as one of their top priorities, often including information about 
adverse drug reactions [4]. Since many patients use medicinal drugs, pharmacovigilance is becoming increasingly important to patient organizations [5-7]. In a study that asked national and international patient organizations about their involvement in pharmacovigilance, around two in five stated that they would like their members to be more aware of adverse reactions to their medicines. Around three in five wanted the pharmacovigilance community to provide information on drug use and adverse drug reactions that they could communicate to their members. In the same study, more than two in five patient organizations said they communicated daily with members on social media [8]. In view of this, an opportunity exists for closer collaboration between patient organizations and pharmacovigilance professionals in communicating adverse drug reaction insights.

The aim of this study was to explore whether collaboration with patient organizations could be an effective way of communicating adverse drug reaction insights to patients. Specifically, (1) how a pharmacovigilance centre can interact with a patient organization to communicate adverse drug reaction insights; (2) how many patients could be reached through these communication channels; (3) how patients would respond to the information; (4) how much of the original (regulatory) signal text needs to be adapted to be useful for patients.

\section{Method}

As a basis for this study, we chose a previously published signal on levothyroxine and panic attacks [9]. This signal was identified in VigiBase, the WHO global database of individual case safety reports, during a signal detection exercise that focused on drug-adverse event combinations reported primarily by patients [10]. We chose to conduct our study on this particular signal because there is a strong causal association between the drug and the event. We also believe that communicating it can have significant real-world impact on patients. The cases described in the signal often reported no or delayed recognition of the drug's role in causing the panic attacks, both by patients and health professionals. Communicating the signal through patient organizations would give patients an opportunity to recognize the adverse event earlier, thus mitigating harm and improving therapeutic outcomes. In addition, Lareb had previous experience in collaborating with the Dutch thyroid organization Schildklier Organisatie Nederland (SON), a not-for-profit entity that promotes the interests of 500,000 patients with thyroid disease in the Netherlands. It is also part of the International Thyroid Federation and the Dutch Patient Federation, the umbrella organization for patient organizations in the Netherlands.

\subsection{Tailoring the Message}

The main message we wished to communicate was that panic attacks, or related signs and symptoms, experienced while using levothyroxine could be an adverse drug reaction to the medicine. Patients who experience these symptoms were advised to consult their treating physician because panic attacks can be a consequence of incorrect levothyroxine dosage.

The original signal [9] was translated from English to Dutch and rewritten to tailor the message to the target audience. We placed special emphasis on what the patient should do if they experienced panic attacks and related symptoms. We also included information about what an adverse drug reaction is and how and why to report adverse drug reactions. Beyond that, language and writing style were adapted to the health literacy level of the target audience, for example by working with clear subheadings and avoiding professional jargon, difficult words and long sentences. The text was written on Common European Framework of Reference for Languages (CEFR) level B1, which is a language level understood by $80 \%$ of the Dutch population. An online tool was used to verify that the text met the B1 level criteria. Two texts were developed: a longer article for the print magazine and a shorter one for the website (see the electronic supplementary material). Both were considerably shorter than the original signal text in the WHO Pharmaceuticals newsletter [9]. The website text was the main piece of information, as the other channels, including the newsletter and social media, linked back to it, see Fig. 1. The Twitter post was shorter than the Facebook post because of the restriction on number of characters in Twitter. The Twitter post was accompanied by the hashtag, \#schildklier (thyroid gland). No other hashtags or key words were used in the social media communications. All texts were accompanied by an image of a woman taking medicines and showing signs of distress. This picture was selected because it represented that target group. Thyroid disease is more common in women than in men [11].

To prompt a reaction from readers, the sentence: Is dit herkenbaar? (Do you recognize this?) was placed at the end of the posts on Facebook.

\subsection{Choosing Appropriate Distribution Channels}

The channels used to communicate the drug safety signal were the Dutch thyroid association's digital newsletter, social media channels (Facebook and Twitter) [12, 13], website [14] and the magazine Schild, a print magazine distributed to all members of the organization. The decision to use several different digital communication 
channels was based on the wide use of internet and social media in the Netherlands: $87.4 \%$ use internet as a communication tool, for example, through social media. Most people access the internet through laptops, tablets and smartphones and to a lesser extent through desktops. In the older age groups ( $\geq 65$ years) the internet is less prominent as a communication tool, so value remains in also using print communication channels [16].

The text was published on the website and patients received the digital newsletter with a link to the online article on 12 December 2018. Two days later, SON posted the information on social media. SON has three different Facebook pages, one public page with 11,000 followers and two private Facebook pages with 9500 followers. A week later, members received the print magazine with the full article.

\section{Results}

The digital newsletter was distributed to around 5000 subscribers. Statistics from Google Analytics showed that the relevant page on the SON website was viewed 1582 times [17]. More than $75 \%$ navigated there via social media links, the rest via the newsletter link. The webpage was viewed most on 14 December 2018, the day of publication, with 1100 views. In the following two days, the page was viewed about 200 times per day.

Three days after the message was posted on Facebook, 13,820 people had the post on their timeline, which means it was accessible for them to read. In total, 2676 engagement actions were seen, consisting of 2346 clicks in the message, which indicates an intention to read the whole post, and 330 reactions. These included 136 emoticon reactions, $136 \mathrm{com}-$ ments and reactions on comments, and 58 shares. Please note that engagement actions were only measured on the open

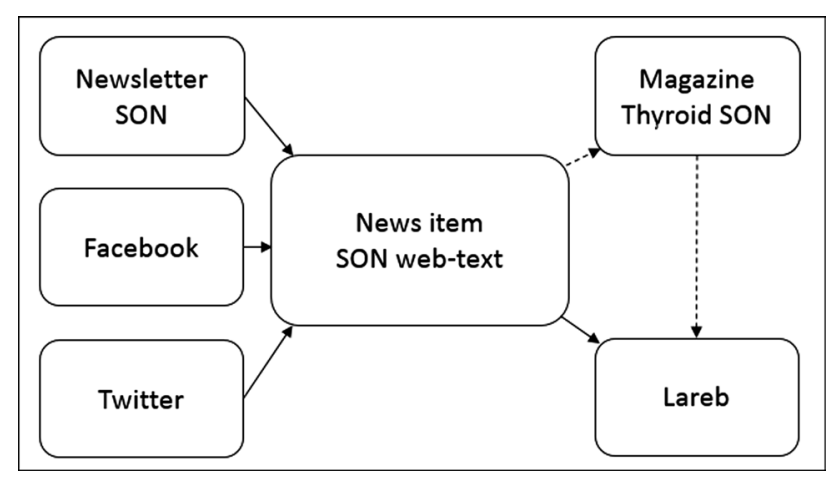

Fig. 1 Model of the communication channels used and how they are linked to each other. SON is the Dutch Thyroid Organisation public Facebook group of SON and not the private Facebook groups. The number of people reached on Twitter was 3000 . The message there attracted five comments and was retweeted 15 times.

The interactions on social media were overall positive and the tone was respectful. A large proportion of patients who commented on the Facebook post responded to the question as to whether symptoms were recognizable. Recognition and acknowledgement of the adverse drug reaction and of the possibility of incorrect dosage were the most common responses. Here are some examples (translated to English by the authors):

"How long have I been saying this?! And now finally recognized."

"Very recognizable. What a panic and fear I have felt."

"I was overdosed a few years ago and then also had fears. Once properly dosed again it was happily gone".

In addition, some responses showed that the term 'side effects' was confusing if symptoms are caused by an excessive dose of levothyroxine:

"This does not seem to be a side effect but a symptom of an overactive thyroid gland."

The Facebook page was moderated by an employee of the Dutch thyroid organization, who responded to such comments with an explanation that symptoms due to an excessive dose of levothyroxine can be considered an adverse drug reaction.

In the print article, patients were encouraged to report adverse drug reactions to Lareb. In the 9 weeks before the communication about panic attacks and levothyroxine, Lareb received a total of 15 reports on levothyroxine. In the 9 weeks after the communication, 18 reports were received, three of which concerned the specific association between panic attacks and levothyroxine. One of these reports referenced the communication from SON.

\section{Discussion}

This pilot study shows that it is possible and valuable to communicate adverse drug reaction signals through patient organizations and reach the desired target audience (here, patients using levothyroxine). The social media post about levothyroxine and panic attacks generated more engagement than other communications in these fora, indicating a strong interest in this information. The additional patient experiences that were shared in the comments on social media further strengthened the original signal and its relevance to patients, creating an interesting feedback loop.

Communication with patients differs from communication within the regulatory system and with healthcare professionals in many ways [18]. When communicating a signal to 
patients, it is important to use a language and style suited to a broader audience. This is a topic that has been extensively researched and where recommendations and 'best practice' are available $[18,19]$. It is also important to provide information on what action the patient could take if they think they are experiencing the adverse drug reaction in question. To increase engagement and prompt a reaction, it can also be helpful to include a question, such as the "Do you recognize this?" with which we ended the social media post in our study.

In re-writing the signal for patients, the writers at Lareb were supported by staff at the patient organization, who have in-depth knowledge of their members and the information they might benefit from. However, this approach is only possible for diseases for which patient organizations exist. For drugs without chronic users, such as antibiotics, there tend not to be specific patient organizations. Also, other patients might not be organized in the same fashion in some areas of the world. For these situations, alternative communication strategies must be deployed.

Even when a relevant patient organization exists, its representatives may not be familiar with pharmacovigilance, in which case it is particularly important to discuss the aim of the communication at the outset of the collaboration. The roles and responsibilities of each party throughout the communication process should be clarified. For example, such an agreement might specify who will moderate the social media channels and what answers should be given to specific questions. In this study, it was agreed that the patient organization would moderate its social media channels but that if they felt unsure of what to answer, they would consult a pharmacovigilance expert at Lareb.

Both Lareb and the patient organization invested a considerable amount of time in this pilot study, from making arrangements to preparing the text and communication materials, to monitoring and evaluating the communication. As many pharmacovigilance centres already have a high workload, there will be a trade-off between working to identify new signals and following through with already identified signals to ensure they reach the appropriate audience. We believe that communication of signals is crucial to minimize harm from drugs and that equal or even higher priority should be given to communication efforts. That said, not all signals will be suitable for direct communication to patients. Signals of uncertain causal relation that provide early warnings before further substantiation may be less suitable. The same may be true for signals of very rare adverse drug reactions, where there is a very small chance that any given patient will be affected. On the other hand, if serious harm can be prevented by recognizing the adverse drug reaction early, such a signal could be communicated more broadly. Any signal where the patient can take preventive measures to reduce harm are of particular importance to communicate.
In this study, Lareb worked with a single organization to reach patients in the same country. As there had been collaboration in the past between the two actors, it is difficult to say how much extra effort a new collaboration would require or whether it would have similar impact.

Although the results of this study are promising, the concept of communicating signals via patient organizations needs to be explored further for other drugs and in other settings before firm conclusions about its usefulness can be drawn. We could only measure the number of people who were reached by the communication, and we could not assess how the information was perceived or whether it had an impact in terms of patients recognizing their panic attack symptoms as possible adverse drug reactions and undertaking action after reading our information. These are important aspects to assess in the future.

It will also be important to explore whether this model can scale to an international level. Although European and other international patient organizations exist, we believe it is most useful for individual countries to communicate adverse drug reaction information via national patient organizations, as they will have direct communication channels to the patients using the drug. Countries may also differ in how drugs are used and the advice given about handling adverse drug reactions. Overall, it is valuable for pharmacovigilance centres and patient organizations to build relationships, especially to promote adverse drug reaction reporting. A first step toward broader communication of signals through multiple patient organizations might be to draft a text in English for the general public and support this with images and infographics that can be used in different countries, regardless of language.

\section{Conclusion}

Communicating adverse drug reaction signals through the channels of a patient organization can effectively reach the target audience. The favourable experience from the perspective of both the pharmacovigilance community and the patient organisation in this study supports further consideration and exploration of this approach to communicating adverse drug reactions.

\section{Compliance with Ethical Standards}

Conflicts of interest Linda Härmark, Gerda Weits, Rietje Meijer, Federica Santoro, G. Niklas Norén and Florence van Hunsel declare that they have no conflicts of interest.

Funding No sources of funding were used to assist in the preparation of this study. 
Data sharing The datasets generated during and/or analysed during the current study are available from the corresponding author on reasonable request.

Open Access This article is licensed under a Creative Commons Attribution-NonCommercial 4.0 International License, which permits any non-commercial use, sharing, adaptation, distribution and reproduction in any medium or format, as long as you give appropriate credit to the original author(s) and the source, provide a link to the Creative Commons licence, and indicate if changes were made. The images or other third party material in this article are included in the article's Creative Commons licence, unless indicated otherwise in a credit line to the material. If material is not included in the article's Creative Commons licence and your intended use is not permitted by statutory regulation or exceeds the permitted use, you will need to obtain permission directly from the copyright holder. To view a copy of this licence, visit http://creativecommons.org/licenses/by-nc/4.0/.

\section{References}

1. Piening S, Haaijer-Ruskamp FM, de Graeff PA, Straus SM, Mol PG. Healthcare professionals' self-reported experiences and preferences related to direct healthcare professional communications: a survey conducted in the Netherlands. Drug Saf. 2012;35(11):1061-72.

2. Sullivan HW, Aikin KJ, David KT, Berktold J, Stein KL, Hoverman VJ. Consumer understanding of the scope of FDA's prescription drug regulatory oversight: a nationally representative survey. Pharmacoepidemiol Drug Saf. 2019.

3. Hugman B. The Erice declaration : the critical role of communication in drug safety. Drug Saf. 2006;29(1):91-3.

4. Brabers A, Schors, W. van der, Jong, J. de. (NIVEL). Zorggebruikers zien patiëntenorganisatie als belangrijke bron voor lotgenotencontact (Healthcare users see patient organization as an important source for contact with fellow patients) 2017 (updated 2017). https ://www.nivel.nl/nl/publicatie/zorggebruikers-zien-patientenorgani satie-als-belangrijke-bron-voor-lotgenotencontact. Accessed 08 Jan 2020.

5. Ayme S, Kole A, Groft S. Empowerment of patients: lessons from the rare diseases community. Lancet. 2008;371(9629):2048-51.

6. Mavris M, Le Cam Y. Involvement of patient organisations in research and development of orphan drugs for rare diseases in Europe. Mol Syndromol. 2012;3(5):237-43.
7. Borup G, Bach KF, Schmiegelow M, Wallach-Kildemoes H, Bjerrum OJ, Westergaard N. A paradigm shift towards patient involvement in medicines development and regulatory science: workshop proceedings and commentary. Ther Innov Regul Sci. 2016;50(3):304-11.

8. Matos C, Weits G, van Hunsel F. The role of European patient organizations in pharmacovigilance. Drug Saf. 2019;42(4):547-57.

9. Norén N, Grundmark, B. Panic attacks with levothyroxine 2017 (updated 2017). https://apps.who.int/medicinedocs/documents/ s23197en/s23197en.pdf. Accessed 08 Jan 2020.

10. Watson S, Chandler RE, Taavola H, Harmark L, Grundmark B, Zekarias A, et al. Safety concerns reported by patients identified in a collaborative signal detection workshop using VigiBase: results and reflections from Lareb and Uppsala Monitoring Centre. Drug Saf. 2018;41(2):203-12.

11. Vanderpump MP. The epidemiology of thyroid disease. Br Med Bull. 2011;99:39-51.

12. Schildklier Organisatie Nederland (SON). Bijwerking van schildkliermedicijn wordt niet altijd herkend. Facebook Post; 2018. https://www.facebook.com/schildklier.nl/ (14-12-2018, accessed 18-12-2019).

13. Schildklier Organisatie Nederland (SON). Bijwerking \#schildklier niet altijd herkend. Twitter; $2018 \mathrm{https} / / /$ twitter.com/schildklier/ status/1073510407489417216?s=19 $(14-12-2018$, accessed 18-12-2019).

14. Schildklier Organisatie Nederland (SON). Bijwerking schildkliermedicijn niet altijd herkend 2019 (updated 2019). https://www. schildklier.nl/nieuws/43-nieuws/538-bijwerking-schildkliermedi cijn-niet-altijd-herkend. (14-12-2018, accessed 18-12-2019).

15. Schildklier Organisatie Nederland (SON). Magazine Schild. 2018:10-1.

16. CBS StatLine. Internet; toegang, gebruik en faciliteiten 2019. https://opendata.cbs.nl/statline/\#/CBS/nl/dataset/83429NED/table ?dl=2F8AA. (09-10-2019, accessed 09-03-2020).

17. Google. Google analytics - measured between December 13, 2018 and January 16, 20192019 (updated 16-01-2019). https://analy tics.google.com/analytics/web/provision/?authuser=0\#/provision.

18. Freeman ALJ. How to communicate evidence to patients. Drug Ther Bull. 2019;57(8):119-24.

19. Buchter RB, Fechtelpeter D, Knelangen M, Ehrlich M, Waltering A. Words or numbers? Communicating risk of adverse effects in written consumer health information: a systematic review and meta-analysis. BMC Med Inform Decis Mak. 2014;14:76. 